\title{
ANALISA PARAMETRIK CHANNEL FLOW PADA LAMBUNG KAPAL CEPAT \\ UNTUK MEMPEROLEH WAKE MAKSIMUM \\ STUDI KASUS: KAPAL CEPAT RUTE AMBON WAYAME
}

\author{
E. R. de Fretes \\ e-mail: defretesera@gmail.com \\ Jurusan Teknik Perkapalan Fakultas Teknik Universitas Pattimura - Ambon
}

\begin{abstract}
ABSTRAK
Peningkatan kecepatan kapal akan menyebabkan kemungkinan berat kapal lebih kecil dari daya angkat hidrodinamika sehingga seakan-akan badan kapal terangkat. Selanjutnya karena kecepatan kapal yang tinggi, maka aliran air menuju baling-baling harus ditata dengan baik untuk mendapatkan efisensi baling-baling yang memadai. Salah satu adalah menggunakan cannal flow pada lambung kapal. Ukuran dan bentuk kanal ini harus didesian dengan baik sehingga menghasilkan speed advance dari aliran yang menuju baling-baling dapat meningkatkan efisiensi dari baling-baling tersebut. Dalam mendesain ukuran dan bentuk dari cannal flow tersebut selain ukuran dan parameter bentuk kapal, bentuk dari kanal harus ditentukan dengan baik. Permasalahan yang terjadi adalah pemborosan bahan bakar yang diakibatkan karena aliran yang masuk ke baling-baling tidak sempurna, dan berpengaruh pada wake fraction yang terjadi, sehingga efisiensi propeller menjadi rendah mengakibatkan pengguaan tenaga mesin induk yang berlebihan dan sangat berpengaruh pada penggunaan bahan bakar yang dihasilkan. Kajian yang disampaikan dalam penelitian ini mengkaji variasi sejumah bentuk dan konfigurasi channel flow, pada khususnya dengan meninjau pada pola aliran yang terbentuk dan wake yang ditimbulkan. Pengkajian dilakukan dengan menerapkan percobaan, dengan model pengujian laboratorium untuk mendapatkan hasil yang menyerupai kondisi sebenarnya. Diharapkan melalui penelitian ini mendapatkan desain awal dari speed boat dengan cannal flow yang nantinya dapat menjawab penggunaan bahan bakar dengan tidak memperhatikan kondisi gelombang. sehingga dapat digunakan secara parsial untuk mengangkut penumpang pada transportasi pulau-pulau terkecil, wake yang dihasilkan kapal untuk satu cannal dan dua cannal dengan konvensional mempunyai nilai meningkat secara linier yakni $4 \%$ dari konvensional dari satu cannal dan dari ke dua cannal adalah $4,21 \%$.
\end{abstract}

Kata Kunci: cannal, flow, speedboat, efisensi propeller, hambatan

\section{PENDAHULUAN}

Pelayaran rakyat sebagai usaha rakyat yang bersifat tradisional yang merupakan bagian dari usaha angkutan perairan. Pelayaran ini menggunakan kapalkapal kecil. Wilayah operasinya adalah di seluruh perairan Indonesia. Pengoperasian kapal-kapal speed boat (kapal cepat berukuran kecil) di perairan Maluku merupakan unjung tombak pelayaran antar pulau dengan radius pelayaran yang pendek yaitu dibawah 3 mil laut, salah satunya adalah pada pelayaran dengan rute kota Ambon-Wayame, yang merupakan salah satu trayek padat di daerah Maluku.

Kapal-kapal speed boat adalah kapal yang Menerapkan hukum archimedes bahwa berat air yang dipindahkan oleh suatu benda sama dengan gaya hidrosytatis ke atas. Dilain pihak dengan bertambahnya kecepatan kapal, maka bertambah juga gaya angkat ke atas dan akan memperkecil volume bagian bawah kapal yang tercelup ke dalam air, dengan peningkatan kecepatan kapal kemungkinan berat kapal lebih kecil dari daya angkat hidrodinamika sehingga seakan-akan badan kapal terangkat.

Selanjutnya karena kecepatan kapal yang tinggi, maka aliran air menuju baling-baling harus ditata dengan baik untuk mendapatkan efisensi baling- baling yang memadai. Salah satu adalah menggunakan cannal flow pada lambung kapal. Ukuran dan bentuk kanal ini harus didesian dengan baik sehingga menghasilkan speed advance dari aliran yang menuju baling-baling dapat meningkatkan efisiensi dari baling-baling tersebut. Dalam mendesain ukuran dan bentuk dari cannal flow tersebut selain ukuran dan parameter bentuk kapal, bentuk dari kanal harus ditentukan dengan baik

\section{KAJIAN TEORI DAN METODE}

Sebagai dasar dalam analisa ini adalah metode Savitsky (1984). Metode ini cocok diaplikasikan pada kapal cepat terutama pada kapal cepat bentuk hard chine, perhitungannya dilakukan dengan menggunakan Froude number.

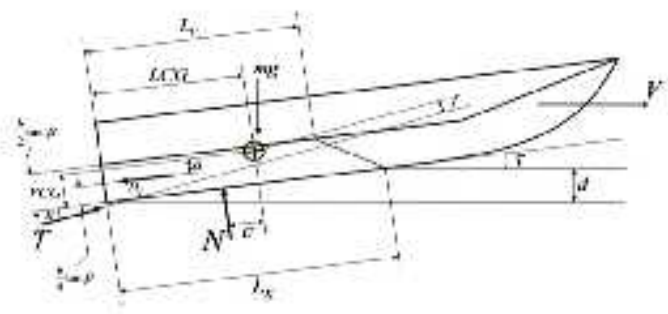

Gambar 1. Kapal saat planing hull 


$$
\begin{array}{ll}
\mathrm{N} \cos \tau+\mathrm{T} \sin (\tau+\varepsilon)-\mathrm{mg}-\mathrm{D}_{\mathrm{f}} \sin \tau & =0 \\
\mathrm{~T} \cos (\tau+\varepsilon)-\mathrm{N} \sin \tau-\mathrm{D}_{\mathrm{f}} \cos \tau & =0 \\
\mathrm{CG} \quad \mathrm{N} . \mathrm{c}+\mathrm{D}_{\mathrm{f} . \mathrm{a}-\mathrm{T} . \mathrm{f}} & =0
\end{array}
$$

Berdasarkan International Maritime Organization (IMO) mendefinisikan untuk kapal cepat, kecepatan masksimum (meter / detik) sama dengan (Bero, 2009):

$$
\mathrm{V} \geq 3.7 \nabla^{0.165 i}
$$

Dimana

$\mathrm{N}=$ hydrodynamic force normal the bottom $(\mathrm{N})$

$\tau=$ trim angle of planing area $(\mathrm{deg})$

$\mathrm{D}_{\mathrm{f}}=$ friction drag component along the bottom

surface $(\mathrm{N})$

$\mathrm{T}=\operatorname{draft}(\mathrm{m})$

$\mathrm{CG}=$ Centre Gravity $(\mathrm{m})$

$\mathrm{a}=$ distance between $\mathrm{D}_{\mathrm{f}}$ and $\mathrm{CG}$ measured normal to

$\mathrm{D}_{\mathrm{f}}(\mathrm{m})$

$\mathrm{c}=$ distance between $\mathrm{N}$ and $\mathrm{CG}$ measured normal to

$\mathrm{N}(\mathrm{m})$

$\mathrm{d}=$ vertical depth $(\mathrm{m})$

$\mathrm{V}=$ velocity (knot)

$\nabla$ adalah deplasemen volume kapal.

Kapal cepat pada saat beroperasi, mulai dari kecepatan (V) 0 knot sampai dengan kecepatan tinggi (kecepatan maksimum) dapat di lihat akan melampaui tiga tahapan (fase) kecepatan sebagai berikut:

\section{a. Fase displasemen $(0,0<\mathbf{F n}<0,6)$}

Kapal-kapal komersial besar hampir selalu berlayar pada fase ini, dimana berat kapal seluruhnya disangga oleh gaya angkat (buoyancy). Kapal yang berlayar dengan kecepatan cukup rendah $(\mathrm{Fn}<0,3)$ tidak akan mengalami perubahan trim ataupun penurunan titik berat (VCG) yang besar. Dengan naiknya kecepatan (Fn) perubahan tersebut mulai timbul. Perubahan ini terjadi akibat naiknya aliran karena bertambah terbenamnya kapal, yang selanjutnya sesuai Hukum Bernoulli, akan berakibat pada penurunan tekanan di bawah kapal bagian buritan dan kenaikan tekanan di bawah haluan kapal.

Dalam kondisi ini akan menarik juga jika diamati sistem gelombang yang terbentuk oleh gerakan kapal. Pada Fn $<0,4$ atau $V_{/ \sqrt{L}}<1.25$ akan terjadi lebih dari satu gelombang melewati sepanjang badan kapal. Pada kecepatan karakteristik kapal Fn $=0,43-0,5$ atau $V / V_{L}=1.4-1.56$ tahanan gelombang relatif akan mencapai maksimum. Diagram tahanan pada Fn ini akan terbentuk kurva melengkung ke atas, atau disebut hump. Sehingga kecepatan kapal disebut juga kecepatan hump. Pada kecepatan yang lebih tinggi (Fn > 0,5), puncak gelombang kedua akan berada jauh di belakang buritan dan tahanan sedikit menurun. Dalam keadaan ini daya angkat ke atas dinamis sama dengan nol.

b. Fase pre-planing $(0,6<$ Fn $<1,2)$ (semi planning) Pada fase pre-planing berat kapal akan disangga lebih banyak oleh gaya angkat hidrodinamik. Gaya angkat hidrodinamik ini timbul karena adanya deviasi aliran di sekitar dasar kapal bagian buritan, sehingga mengakibatkan kapal trim. Dari berbagai pengukuran tes model didapat bahwa pada fase ini titik berat kapal akan naik. Pada sekitar Fn $=0.6$, VCG mencapai ketinggian yang sama dengan pada saat $\mathrm{V}=0$ knot dan selanjutnya VCG terus naik sampai kecepatan karakteristik Fn $=1,2$ dicapai. Dari kecepatan $\mathrm{v}=0$ knot sampai dengan Fn $=0,9$ haluan kapal akan terus naik ke arah permukaan, sedangkan buritanya akan berangsur-angsur terbenam. Pada sekitar $0,9<$ Fn $<1,2$ buritan kapal akan mulai naik lagi, tetapi tidak begitu besar sampai dengan munculnya haluan. Dengan demikian trim akan tetap naik sampai dengan $\mathrm{Fn}=1,2$ dicapai.

Pada fase pre-planing gelombang haluan mengecil dan bergeser ke belakang serta dilengkapi oleh spray (semburan). Dibelakang transom (buritan rata) terjadi lembah gelombang, yang bentuk dan ukurannya sangat bergantung pada bentuk buritan kapal, trim dan terutama juga pada gaya angkat hidrodinamis. Dalam keadaan ini, berat kapal sama dengan sebagian gaya hidrostatis,

\section{c. Fase planing $(\mathbf{F n}>1,2)$}

Fase planning dapat ditandai dengan kondisi dimana hampir seluruh berat kapal disangga oleh gaya angkat hidrodinamik, dan hanya sebagian kecil berat kapal yang bertumpu pada gaya hidrostatik yang juga kecil. Meskipun kapal hampir seluruhnya meluncur di permukaan air, dan permukaan basahnya menjadi sangat kecil demikian juga trim kapal mulai menurun dibandingkan dengan pada fase pre-planing, tetapi tekanan hidrodinamik menjadi sangat besar sebagai akibat kecepatan tinggi yang diperoleh dari gaya dorong propeller. Pada fase planing, bagian kapal yang terbenam sangat kecil, sehingga gelombang yang terbentuk hampir hilang sama sekali. Dalam keadaan ini, gaya angkat keatas mendekati nol, sehingga $\mathrm{P}=\mathrm{Ad}$

Bentuk planing hull paling sederhana adalah bidang datar yang diilustrasikan pada gambar 2. Pengaruh penting dari aliran adalah tinggi water level permukaan air tenang sebagai akibat dari planing. Akibatnya panjang permukaan basah yang dinamis ( L ) lebih besar dari pada yang terendam ( $\mathrm{Li}$ ). Kedua panjang ini berbeda dengan panjang stasioner (Lo). Leading edge dari permukaan basah secara nominal didefinisikan oleh lokasi spray-root line. Kelengkungan permukaan biasanya diabaikan dalam perhitungan.

Arus (Wake) ikut merupakan perbedaan antara kecepatan kapal dengan kecepatan aliran fluida pada 
piringan propeller (propeller disc), yang dapat terjadi karena pengaruh lambung kapal (terutama bentuk streamline dari stern frame) atau karena gerakan propeller yang menimbulkan arus di sekitarnya sesuai arah geraknya.

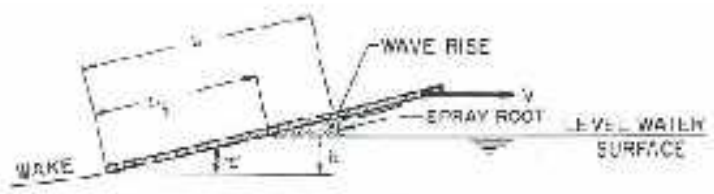

Gambar 2. Geometri sederhana dari permukaan planning (Savitsky, 1964)

Taylor mendefinisikan fraksi arus ikut (wake fraction) sebagai koefisien $w$ [Harvald, 1992], dengan persamaan

$$
\begin{aligned}
& \qquad w=\frac{V_{S}-V_{A}}{V_{S}} \\
& \qquad V_{A}=V_{S}(1-w) \\
& \text { dimana } \\
& V_{S}=\text { kecepatan kapal } \\
& V_{A}=\text { kecepatan advance, yaitu kecepatan maju } \\
& \text { propeller yang merupakan kecepatan relatif dari } \\
& \text { partikel air yang melewati propeller disc atau selisih } \\
& \text { antara kecepatan fluida yang meninggalkan propeller } \\
& \text { (discharge velocity) terhadap kecepatan fluida yang } \\
& \text { masuk propeller (suction velocity). }
\end{aligned}
$$

\section{HASIL DAN PEMBAHASAN}

Dalam pengujian model dilakukan dengan pembuatan model yang dilakukan dengan menggunakan skala kesamaan geometris (skala model) hasilnya dapat dilihat pada gambar 3 .

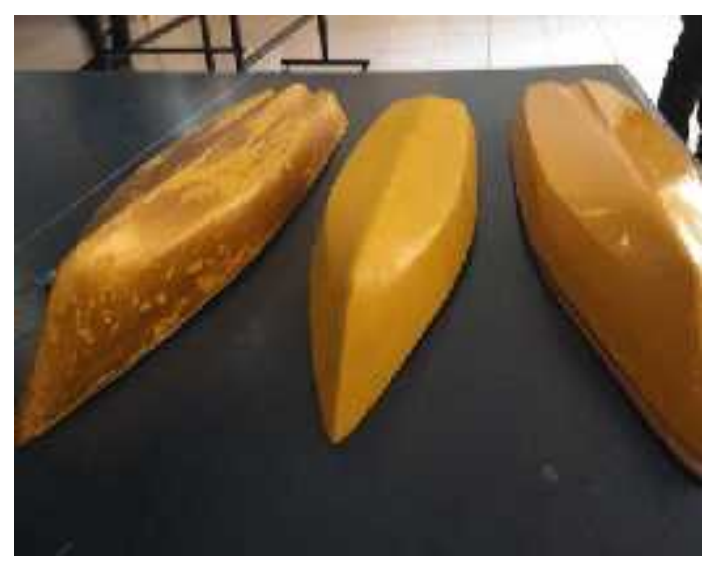

Gambar 3. Model kapal

Di dalam uji laboratorium ini akan di analisa kecepatan model dari setiap beban dengan jarak waktu tertentu. Lokasi berada di lab towing tank. Di dalam percobaan ini dilakukan pada kondisi air yang tenang. Pada saat percobaan model (gambar 4) terjadi lift untuk kondisi kapal konvensional, dua terowongan serta satu terowongan terjadi kenaikan rata-rata sudut kemiringan dari even keel adalah 4,5 derajat pada bilangan Froude $(\mathrm{Fn})=2,2$

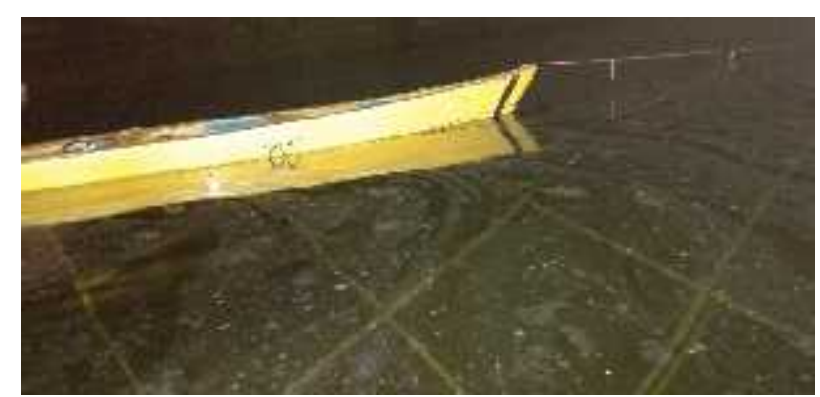

Gambar 4. Percobaan model

Hasil percobaan model dapat dilihat pada tabel 1 untuk hambatan model.

Tabel 1. Hasil percobaan resistance

\begin{tabular}{|c|c|c|c|c|}
\hline No & Model & Resistance pada 6 Knot (KN) & Numerik komputasi & Selisih \\
\hline 1 & Konvensional & 12,11 & 11.85 & $2.15 \%$ \\
\hline 2 & Chainal satu & 18,73 & 17.3 & $7.63 \%$ \\
\hline 3 & Chainal dua & 22,42 & 20.82 & $7.14 \%$ \\
\hline
\end{tabular}

Pengaruh hambatan kapal jika dilihat dari table 1 diatas, diperoleh bahwa rata-rata perbedaan antara cfd denagn pengujian adalah 5,64\%, atau boleh dikatakan sudah valid untuk hasilnya. Sedangkan semakin banya chainel yang dibuat, semakin besar hambatan yang diperoleh. Atau untuk konvensional dan satu chanel mempunyai perbedaan $123 \%$ lebih besar satu chanel, sedangkan antara satu chanel dengan dua channel adalah $145 \%$ lebih besar dua channel. Untuk menentukan besarnya wake, maka menggunakan pendekatan CFD dengan memperoleh variasi kecepatan (vector kecepatan) untuk masing-masing variasi bentuk channel .

Setelah melakukan meshing geometri, maka langkah selanjutnya adalah penentuan kondisi batas. Kondisi batas itu adalah inlet, outlet, dan wall, dalam menentukan kondisi batas inlet adalah kondisi di mana aliran memasuki boundary condition. Kondisi batas inlet dan menandakan chord frame agar hasil akhirnya bias menampilkan garis chord dari boundary condition.

Gambar 5 menunjukan Analisis grid independensi pada penelitian ini dilakukan dengan menggunakan 4 model grid dengan jumlah sel yang berbeda. Jenis grid yang dipilih sama yaitu 1986000 tiap-tiap mesh dilakukan perhitungan model kapal dengan kecepatan 8 knot konvergensi dapat dicapai pada skala residual $10^{-6}$.

Pada penelitian ini dipilih grid dengan model tetrahedra dan dilakukan inflated dengan jumlah 10 layer dan rasio inflated 1,2 hal ini dimaksudkan yaitu membuat lapisan tipis pada elemen meshing didekat lambung kapalselam, agar model yang disusun mempunyai sel lebih sedikit. Sehingga dengan meningkatkan kerapatan mesh, tidak diperoleh 
tambahan jumlah elemen yang signifikan. Pada tahapan ini ditentukan surface yang dipilih untuk menjadi daerah boundary condition.

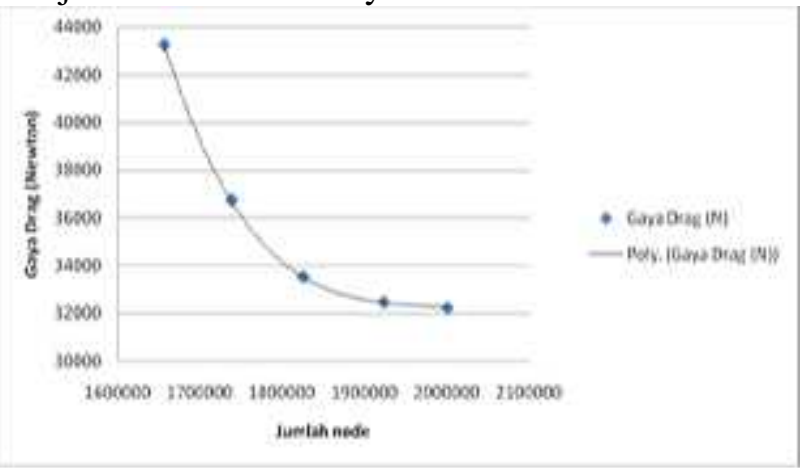

Gambar 5. Hasil grid independence

Jumlah elemen yang optimal ditentukan dengan cara memvariasikan jumlah elemen pada Mesh Parameter dan Mesh Control untuk suatu titik. Bila perubahan sel-sel sudah tidak mempengaruhi hasil atau nilai akhir iterasi, maka dipilih elemen yang paling rendah untuk dipergunakan sebagai acuan dalam proses eksekusi pemograman. Seterusnya Untuk mengecek jarak non dimensional dari dinding dengan grid pertama di mana tingkat turbulensi dapat diklasifikasikan disebut $\mathrm{Y}^{+}$[Khor Y. S, Xiao Q, 2011]. Dalam eksperiment numerik disini, seperti terlihat pada Gambar 28, nilai yang $\mathrm{Y}^{+}$diperoleh adalah 154,127 . Nilai $\mathrm{Y}^{+}$yang diperoleh ini masuk dalam rentang yang direkomendasikan oleh Anderson (1995) yakni antara 30-500

Dengan menggunakan model yang dilakukan dengan CFD, maka hasil yang diperoleh adalah hasil hambatan dan divalidasikan dengan hasil dari towing tank. Hasil inilah yang dipakai sebagai acuan untuk menentukan kecepatan aliran yang masuk ke balingbaling. Wake yang terjadi pada aliran di sekitar kapal akan ditentukan oleh perbandingan kecepatan aliran di sekitar lambung kapal yang dalam hal ini adalah sama sepanjang kapal dibanding dengan kecepatan aliran yang masuk ke propeller (speed of advance). Untuk itu pengambilan speed advance harus dilakukan pada tempat di mana akan diletakan propeller, seperti dapat lihat pada Gambar 6. Dari profil kecepatan ini, dengan menggunakan akar kuadrat rata-rata (Root Mean Square) maka akan dapat ditentukan speed advance untuk tiap-tiap variasi kecepatan, di samping itu bentuk lambung dan bagian-bagian tambahan juga mempunyai penting pada nilai wake suatu kapal. Setrusnya dengan variasi kecepatan aliran yang masuk di baling-baling, dengan mengcapturenya pada daerah baling-baling diperoleh variasi kecepatan.

a.
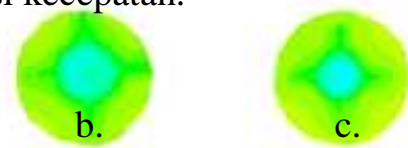

Gambar 6. Distribusi kecepatan untuk kapal speed boat
a. konvensional,
b. channel satu,
c. channel dua

Dapat dilihat bahwa distribusi kecepatan untuk lambung konvensional, mempunyai kecapat lebih kecil jika dibandingkan dengan satu chanel dan selanjutnya untuk dua channel.

Dengan menggunakan pendekatan Root Mean Square (RMS) maka diperoleh besar wake yang diperoleh untuk masing-masing kondisi. Variasi tersebut dapat dilihat pada table 2 berikut ini.

Tabel 2. Hasil Percobaan Wake

\begin{tabular}{|c|c|c|}
\hline No & Model & Wake yang dihasilkan \\
\hline 1 & Konvensional & 0.06667 \\
\hline 2 & Chainal satu & 0.06421 \\
\hline 3 & Chainal dua & 0.06386 \\
\hline
\end{tabular}

Dari hasil pada table diatas dapat dianalisis bahwa rata-rata wake yang dihasilkan oleh bentuk konvensional adalah 0,6667 sedangkan untuk chanel satu sebesar 0,6421 sehingga mempunyai perbedaan $4 \%$, sedangkan untuk dua chanel yaitu 0,6386 atau terjadi peningkatan dengan model konvesional adalah $4,21 \%$. Sehingga dapat disimpulkan bahwa model dua chainel mempunyai wake yang baik jika dibandingkan dengan model satu chanel dan model konvensional, namun model konvensional dari sisi resistance mempunyai nilai yang lebih kecil jika dibandingkan dengan model satu chanel dan dua chanel. Demikian juga untuk hasil resisrtance dari model satu chanel dengan dua chanel mempunyai peningkatan lebih besar.

\section{KESIMPULAN}

1. Semakin banyaknya jumlah satu channel maka besar pengaruh bentuk lambung tersebut terhadap hambatan kapal bentuk konvensional sebesar $123 \%$ dari sebelumnya, sedangkan untuk dua dan satu chanel mempunyai perbedaan $145 \%$

2. Untuk Wake kapal satu chanel mempunyai kecenderungan lebih baik jika dibandingkan dengan konvensional yaitu 4\%, jika dibandingkan konvensional dengan dua chanel adalah $4.21 \%$

\section{DAFTAR PUSTAKA}

Royal Institution of Naval Architects, 2004, Ship \& Boat International March/April Edition, Pensord Press Ltd, London, UK

Parsons, Michael G., 2003, Ship Design and Construction, The Society of Naval Architects and Marine Engineers, Jersey City, NJ, USA

Watson, D., 1988, Practical Ship Design, Vol.1, Elsevier Science Ltd., Kidlington, Oxford, UK

Effendy Junaedy, 2006, Analisa Teknis Perencanaan Kapal Patroli Cepat Dengan Bentuk Hull Katamaran, Tugas Akhir-LK 1347, ITS 
Surabaya

Jamaluddin A., 2012, Kajian Eksperiment dan Numerik Interferensi Hambatan Viskos dan gelombang Pada Lambung Katamaran, Disertasi Program Doktor Program Studi Teknik Kelautan, ITS-Surabaya

Insel, M. and Molland, A. F., 1992, An Investigation
Into the Resistance Components of High Speed Displacement Catamaran, The Royal Institution of Naval Architects, London, England

Savitsky Daniel, 1964, Hydrodynamic Design of Planning Hull, Marine Technology, Vol. 1, No 1, October, pp. 71-95 